\title{
A “experiência” em cartas dos jesuítas missionários no Brasil nas primeiras décadas do século XVI
}

The "experience" in letters of Jesuit missionaries in Brazil in the
first decades of the sixteenth century

Marina Massimi ${ }^{*}$

\begin{abstract}
Resumo
O artigo analisa os sentidos do termo experiência assim como empregado por jesuítas em missão no Brasil, nas primeiras décadas do século XVI, em cartas por eles redigidas. Tais sentidos são apreendidos à luz do arcabouço conceitual da Companhia de Jesus. São evidenciadas três significações da experiência: a experiência como prova e verificação; a experiência como prática e hábito; a experiência como discernimento da presença do mistério nos fatos. O conjunto destas significações remete à experiência modelo do fundador da Companhia, Inácio de Loyola, onde o conhecimento da realidade sensível e imanente remete sempre ao conhecimento da realidade espiritual transcendente.
\end{abstract}

\section{Palavras Chave}

Experiência; cartas jesuíticas; jesuítas no Brasil; história dos saberes no século XVI; cultura jesuítica.

\begin{abstract}
The article examines the meanings of the term experience as employed by Jesuits on mission in Brazil in the first decades of the sixteenth century, in letters written by them. Such meanings are apprehended in the light of the conceptual framework of the Society of Jesus. Are evidenced three meanings of the experience: the experience as proof and verification; experience as a practice and habit and experience as discernment of the presence of the mystery of the facts. All these meanings refers to the model of the experience of the Company founder, Ignatius of Loyola, where knowledge of sensible reality immanent and always refers to the knowledge of the transcendent spiritual reality.
\end{abstract}

\footnotetext{
* Professora Titular Faculdade de Filosofia Ciências e Letras Universidade de São Paulo Campus de Ribeirão Preto.
}

92 Marina Massini. A “experiência” em cartas dos jesuítas missionários no Brasil... 92-111. 


\section{Keywords:}

Experience; Jesuit letters; Jesuits in Brazil; history of knowledge in the sixteenth century; Jesuit culture.

Recibido: 9 de julio de 2013

Evaluado: 16 de julio de 2013 


\section{Introdução}

O artigo visa entender os sentidos do termo experiência assim como aparece num determinado gênero de fonte histórica: as cartas jesuíticas escritas do Brasil no século XVI.

Cabe lembrar que a escrita da carta num dado universo obedece a exigências históricas e culturais de estilo retórico e poético ${ }^{1}$ : a carta dos Jesuítas, em particular, não é absolutamente uma "taboa rasa, marcada por acontecimentos vividos (...), mas deve ser vista como uma espécie de mapa retórico do progresso de sua conversão"². Desta forma, a possibilidade de sentido e expressão do texto é restrito aos "roteiros plausíveis do mapa" ${ }^{3}$. Existem pelo menos quatro tipos diferentes de escrita de uma carta: persuasivo (o estilo que reconcilia, exorta, dissuade, consola, problematiza ou recomenda), demonstrativo (o estilo descritivo de coisas, pessoas ou lugares, eventos viagens, etc), judicial (o estilo que acusa, ameaça, etc...) e narrativo (que informa, comunica sentimentos).

Na visão de Inácio de Loyola e dos jesuítas, de um modo geral, a composição das cartas seguia a fórmula retórica tradicional do ars dictaminis: a primeira parte chamada a saudação breve, onde o autor expressa sua consideração para com o destinatário, assume o caráter do preâmbulo preparatório; uma segunda parte chamada captatio benevolentiae, ou início, no qual o remetente, organizando as palavras de forma adequada, procura influenciar efetivamente a mente do destinatário, obtendo o favor, e um terceiro que é a narratio onde é informado o assunto em questão e o pedido objeto da missiva, relatando argumentos a favor do pedido, e, finalmente, a petitio e a conclusio, onde o autor repete o pedido de uma forma que é impressa na mente do destinatário e cumprimentá-lo ${ }^{4}$. Importar lembrar também que as cartas dentro da Companhia de Jesus adquirem uma tripla função: informar, reunir em um só corpo e comunicar experiências místicas, ou devocionais. Esta estrutura é codificada pelos documentos institucionais da Companhia de Jesus ${ }^{5}$. Nas Constituições da Ordem, especialmente na terceira parte dedicada ao progresso e conservação daqueles que estão em período de teste, é indicada como sendo um instrumento para a "conservação no que diz respeito à alma", a leitura de cartas edificante "(Const. . § 252) durante as refeições. Na Parte quarta, é exigido ao reitor de cada colégio que a cada ano escreva ao Padre Geral e duas vezes por ano ao Provincial (Const., § 507). O parágrafo 673, do primeiro capítulo na oitava parte do mesmo documento dedicado ao que ajuda a unir a cabeça aos membros que estão distantes) reafirma a importância da escrita de cartas entre os membros, superiores e inferiores, do corpo da Sociedade. Além desses documentos normativos, a correspondência elaborada pelo fundador da Ordem e pelas figuras exemplares, são os modelos sempre disponíveis para serem lidos e imitados ${ }^{6}$. Como lembra Lamalle ${ }^{7}$ (1981-1982), o rápido crescimento e expansão da Companhia, tornou necessário adaptar as regras da redação da correspondência às novas circunstâncias.

\footnotetext{
${ }^{1}$ Pécora, A., 1999: 373.

${ }^{2}$ Ibidem: 373.

${ }^{3}$ Ibidem: 374

${ }^{4}$ Pécora, A., 2001.

${ }^{5}$ Pécora, 1999.

${ }^{6}$ Cardoso, A. SI, 1990.

${ }^{7}$ Lamalle, E., 2004.
} 


\section{A experiência nas fontes jesuíticas do século XVI}

Para entendermos na correspondência epistolar dos missionários jesuítas, o uso do termo experiência será preciso analisá-la à luz do universo cultural próprio da Companhia de Jesus na época. O entendimento do significado da experiência na cultura jesuítica da Idade Moderna é proporcionado por diferentes tipos de fontes ${ }^{8}$. Com efeito, conforme observa Pacheco9: "tal como é empregado entre os jesuítas, o termo experiência deve ser entendido a partir de um complexo feixe de influências": dentre elas destaca, as influências filosóficas: a posição filosófica aristotélico-tomista assumida como ponto de referência na formação jesuítica; e a influência agostiniana ${ }^{10}$. Além disto, a experiência é também uma categoria que pertence ao universo da "regulação tanto espiritual e corporal quanto jurídica e institucional” da Companhia ${ }^{11}$. Ainda segundo Pacheco, a experiência, no âmbito jesuítico, é antes de mais nada um modo de conhecer a realidade, conforme evidenciado pelas palavras do padre jesuíta, Alexandre de Gusmão (1629-1724) ${ }^{12}$, no prólogo de sua obra Eleyçam entre o bem e o mal eterno:

Se fosse considerável hum homem tão simples ou tão ignorante, que duvidasse, se o fogo queimava, y a água esfriava, este tal, com nenhuma outra razão se poderia desenganar melhor, que com a experiência, pondo uma mão no fogo e outra na água. Logo se desenganaria, e veria por experiência, que o fogo queimava e a água esfriava.

Loyola refere-se freqüentemente à experiência nos Exercícios Espirituais.

Com efeito, a própria redação do texto nasceu, como o próprio Inácio relata, de uma experiência: "mas, na medida em que observava algumas coisas na sua alma e as achava úteis, e lhe parecia que poderiam ser também úteis aos outros; então as punha por escrito" ${ }^{\text {" }}$. O livro é um conjunto de instruções diversas destinadas a suscitar nos leitores uma experiência similar, através de número de exercícios interiores sistematicamente ordenados ${ }^{14}$.

No capítulo "Três Tempos para Fazer Boa Eleição”, 15 Inácio afirma, explicando quando se há de fazer uma boa eleição, que um momento propício é aquele no qual "se recebe suficiente luz e conhecimento pela experiência das consolações e desolações, e pela experiência do discernimento dos espíritos" (par.176). Fala também de "experiência de desolação" e "experiência de discernimento dos espíritos".

Pacheco ${ }^{16}$ comenta que os Exercícios Espirituais pretendem ser um percurso que leva ao conhecimento da realidade: "através do transcender a dimensão das operações discursivas e do recorrer à arte da memória e da imaginação”, "o exercitante é

\footnotetext{
${ }^{8}$ Caeiro, F. G., 1982; Caeiro, F. G., 1989.

9 Pacheco, P.R.A. 2004: 59.

10 Para uma discussão acerca do conceito de experiência ao longo da história dos saberes vide Massimi, M. \& Mahfoud, M., 2007.

11 Pacheco, 2004: 12.

12 Gusmão, A., 1720: I.

13 Loyola, 1991: 1072.

${ }^{14}$ Guibert, J., 1953.

${ }^{15}$ Loyola, I., 1991: 142.

${ }^{16}$ Ibidem, p. 67.
} 
convidado a, fazendo uso da memória e da imaginação, construir uma ponte entre o abstrato de uma afirmação e sua imagem concreta na alma." Nisto se evidencia a preocupação de Inácio com a "aplicação dos sentidos”. Para ele, seguindo a visão aristotélico-tomista, a consistência última da realidade é apreendida pelos sentidos ver, tocar, ouvir, degustar, sentir o cheiro -, e não por um exercício de abstração metafísica. Desse modo, a experiência enquanto sensação, sentimento e intuição abre à experiência do transcendente, do divino: a experiência sensível bem orientada é o caminho para atingir também a experiência mística.

Pacheco coloca que "outro documento da ratio spiritualis jesuítica” onde se encontram referências à experiência é o Diário de Moções Interiores, de Inácio, fruto "do trabalho pessoal de "eleição sobre a pobreza", que o fundador fez enquanto preparava o texto das Constituições”, "maço de folhas autógrafas a que se deu o nome de Diário" pelo fato de tratar-se de "notas advindas de uma elaboração da experiência pessoal" ${ }^{17}$. A respeito deste mesmo texto, Pacheco se refere à interpretação de Marin ${ }^{18}$, que denomina o texto de "autobiofonia”, por tratar-se de "um documento no qual Inácio é dado ao leitor como um "imitável, um modelo", cuja leitura convida o destinatário a reviver e imitar as vivências do fundador, repetir a vida do fundador. A leitura do Diário adquire assim, segundo Marin, dignidade sacramental, por proporcionar uma espécie de comunhão eucarística: o texto pode se tornar corpo em seu leitor: a "experiência pessoal de Inácio que é dada como paradigma de identificação e incorporação (...), ou, nos termos próprios da gramática de uso jesuítica, simplesmente imitação"19. Inácio torna-se um modelo imitável, um texto vivo para seus companheiros, que, a partir da eleição de sua liberdade, podem decidir encarnar em suas vidas essa "experiênciamodelo".

A concepção filosófica da experiência segundo os jesuítas é sintetizada pela formulação de Manuel de Góis, o autor de vários dentre os Comentários Conimbricenses $^{20}$, o qual ao discutir acerca do bem e da finalidade das ações humanas, afirma que: “aquilo que pode ser experimentado [quid potest ab aliquo experi] por alguém e alcançar a natureza de fim em relação a alguém, pode ser-lhe bem e conveniente ou ao menos ser apreendido como tal”21. A experiência é adquirida após o agir (modum operandi) e o precedente (e/ou consecutivo) pensar (modum cogitandi) com envolvimento de todas as potências anímicas e conduz à verdade e ao bem. Neste sentido, todas as potências anímicas devem ser envolvidas; sendo que a ação humana é sempre orientada na direção de um fim, cuja eleição depende por sua vez do movimento da vontade e do intelecto, beom como da sensibilidade e dos afetos.

Parece, portanto, que os pensadores da Companhia utilizam o termo nos sentidos aristotélicos de empeiria - a saber, experiência no sentido de habilidade e prática -, de

\footnotetext{
${ }^{17}$ Pacheco, 2004: 69.

${ }^{18}$ Marin, L., 1999.

${ }^{19}$ Pacheco, 2004: 70.

${ }^{20}$ Com o rotulo de Conimbricenses ou de Curso Conimbricense, se entende o conjunto de textos publicados entre 1592 e 1606 com o título de Comentários do Colégio Conimbricense da Companhia de Jesus. A maior parte dos textos títulos é de autoria do P.e Manuel de Góis. Os comentários estão estruturados em torno do texto aristotélico, focado em quaestiones onde são desenvolvidos os temas propostos pela obra aristotélica, mas sem se fixar à "letra do texto". Dentre eles, o Comentário à Ética a Nicómaco, a que aqui nos referimos, é organizado em torno de nove Disputationes que abordam, sumariamente, alguns dos temas da obra de Aristóteles e de Tomás de Aquino

${ }^{21}$ Góis, M., 1957/Original: 1593: 93.
} 
peira - ou seja, prova e experimento - e de aisthesis - a saber, sensação, sentimento e intuição $-{ }^{22}$.

Existe também, como acenamos, a influência da visão de experiência de Agostinho, tida como conhecimento da realidade sensorial e também como conhecimento das realidades transcendentes. Com efeito, no tratado $A$ Trindade ${ }^{23}$ (livro IV, capítulo 20), Agostinho usa o termo "experiência" para referir-se a outro tipo de conhecimento que não o sensorial: o conhecimento do "Verbo de Deus", que "pode ser conhecido e percebido pela capacidade da alma racional, que tende para Deus ou já é perfeita em Deus" ${ }^{24}$. Neste momento, o autor usa o verbo percipitur que significa conhecimento experiencial (no sentido de "ciência saborosa", ou seja, de um entendimento que envolve também a sensação e o afeto) ${ }^{25}$.

A referência à experiência comparece freqüentemente nos textos de Góis assim como nos demais escritos filosóficos da Companhia. Nos referidos Tratados Conimbricenses, com freqüência as teses doutrinárias são comprovadas por afirmações do tipo: "comprova-se esta verdade por meio da experiência", "como a experiência quotidiana ensina”, "a experiência demonstra-o”, "confirma-se por experiência”26.

O tema da experiência é comum também nos escritos jesuíticos de outra natureza e finalidade. A "experiência das coisas" é uma das categorias usadas para classificar os indivíduos pertencentes à Ordem, que comparecem nos Catalogos Segundus, documentos elaborados a cada triênio pelos provinciais da Companhia, onde se descreve a situação de cada membro e de cada residência nos diversos locais de presença da Ordem ${ }^{27}$.

A experiência também é citada pelos pregadores jesuítas em seus sermões ${ }^{28}$. Num curioso sermão pregado no ano de 1665, em Salvador da Bahia, Brasil, pelo padre jesuíta $^{29}$ Lourenço Craveiro, tem-se o uso constante do termo experiência para comprovar a veridicidade das "receitas" sugeridas pelo pregador. Trata-se de receitas metafóricas para o alimento da vida espiritual, baseadas em analogias referentes ao alimento da vida do corpo: aqui o termo experiência (empregado dez vezes ao longo do discurso) assume ambas as conotações (presentes na tradição filosófica, teológica e monástica, especialmente em Bernardo de Claraval) de: experimentar os efeitos da comida pela via sensorial e de conhecimento espiritual. ${ }^{30}$. O termo final deste

\footnotetext{
${ }^{22}$ Cf. Fabris, A. (1997). Esperienza e mistica. Em:A. Molinaro e E. Salman. Filosofia e mistica: itinerari di un progetto di ricerca. (pp. 13-28). Roma: Pontificio Ateneo Sant'Anselmo.

${ }^{23}$ Agostinho, 2000/Original de 416 d.C.

${ }^{24}$ Ibidem: 183.

${ }^{25}$ Massimi, M. \& Mahfoud, M., 2007.

${ }^{26}$ Por exemplo, no comentário ao De Anima aristotélico, encontram-se várias referências deste tipo: vide: Góis, M., 2005/1598: 35; ibidem: 73; ibidem: 128; ibidem: 132; ibidem: 141; ibidem: 156; ibidem 157; Outros comentários importantes aos textos aristotélicos que consultamos são: Góis, 1957/1593; Góis, M., 1607; Góis, M., 1593ª Góis, M., 1602.

${ }^{27}$ Massimi, M., 2000.

${ }^{28}$ Massimi, M. \& Mahfoud, M., 2007.

${ }^{29}$ Merenda eucarística e sermão que pregou o padre Lourenço Craveiro da Companhia de Jesus, da Província do Brasil, do Colégio da Bahia, no terceiro dia das quarenta horas á tarde em 16 de fevereiro de 1665. Deu á estampa o P. Fr. Antonio Craveiro pregador e religioso capucho da Ordem de Nosso Seráfico Padre São Francisco da Província de Granada.

30 "Se as almas febricitantes, enfermas, comerem esta galinha desta sorte adubada, ser lhes ha mui proveitosa: pisem e mortifiquem o corpo, esqueçam-se das delicias, e regalos do mundo, que quiserem
} 
conhecimento por experiência é a identificação com o objeto experimentado: a união mística. O convite do pregador introduz os ouvintes para comprovar suas palavras: a todos é possível adquirir pela experiência o conhecimento mais elevado possível ao ser humano: o da própria Pessoa divina.

Em pesquisa anteriormente desenvolvida já verificamos que na correspondência epistolar encontram-se expressões como "vê-se pela experiência", "comecei a compreender pela experiência”, “a experiência obriga-me a ter esta opinião"31. Dando continuidade a esta primeira investigação, nos propomos agora a estudar os sentidos do termo experiência assim como empregado pelos autores jesuítas das cartas enviadas do Brasil no século XVI, nas primeiras décadas de sua presença nesta terra, especialmente no período entre 1549 e 1560.

\section{Sentidos da experiência nas cartas de jesuítas no Brasil no século XVI}

Analisamos as cartas de Manuel da Nóbrega ${ }^{32}$, José de Anchieta ${ }^{33}$ e outros jesuítas presentes no Brasil nas primeiras décadas da missão nesta terra. Observamos

tomar o gosto a este regalado bocado, e acharão por experiência. Que a quem mortifica o corpo, e se esquece do mundo, é muito gostosa e proveitosa iguaria o Divino Sacramento" (Craveiro, ibidem:6).

31 Massimi, M.; Mahfoud, M.; Silva, P. C. J.; Avanci, S. H. S. (1997). Navegadores, colonos, missionários na Terra de Santa Cruz: um estudo psicológico da correspondência epistolar. São Paulo: Loyola.

32 Manuel da Nóbrega nasceu em 1517 do desembargador Baltasar da Nóbrega. Estudou durante quatro anos na Universidade de Salamanca e depois na Universidade de Coimbra, bacharelando-se em direito canônico e filosofia em 1541, recebendo o grau de bacharel em cânones. Aos 27 anos, foi ordenado pela Companhia de Jesus em 1544, fazendo-se pregador. Viajou por Portugal e Espanha na pregação do Evangelho. Por um convite do rei D. João III, embarcou na armada de Tomé de Sousa para o Brasil em 1549. Chegou a Salvador na Bahia em 29 de março de 1549. Foi dele amigo e conselheiro de Tomé de Sousa e de Mem de Sá, ambos governadores a serviço da Coroa. A missão dos jesuítas era voltada para a catequese dos indígenas. Junto com Nóbrega, chegaram ao Brasil, os jesuítas Leonardo Nunes, João de Azpilcueta Navarro, Antônio Pires e os irmãos jesuítas Vicente Rodrigues e Diogo Jácome. Nóbrega deu início ao trabalho de catequese dos indígenas, desenvolvendo uma intensa campanha contra a antropofagia existente entre os nativos e ao mesmo tempo combatendo a sua exploração pelos colonos. Participou da fundação das cidades do Salvador e do Rio de Janeiro. Atuou na luta contra a invasão dos franceses como conselheiro de Mem de Sá. Passou a vida em constantes viagens a pé, barco e mula por toda a costa do Brasil, de São Vicente a Pernambuco. Participou da fundação da vila de São Paulo que viria a ser o ponto de penetração para o sertão e de expansão do território brasileiro e mais tarde tornou-se a mais importante cidade de hemisfério sul. A primeira missa foi ali rezada por Nóbrega em 29 de agosto de 1553. Junto com José de Anchieta, desembarcado no Brasil como noviço em 1553, no trabalho de pacificação dos Tamoios em Iperoig, em 1563, que retiraram apoio aos invasores franceses, finalmente derrotados. Acompanhou a expedição de Estácio de Sá, encarregado de fundar uma cidade, São Sebastião do Rio de Janeiro, de cuja fundação participou, ali construiu um colégio jesuíta. Nóbrega solicitou ao rei de Portugal, Dom João III, a criação da primeira diocese no Brasil, e em decorrência desse pedido, Dom Pero Fernandes Sardinha, primeiro bispo do Brasil, foi enviado para Salvador. Em 1558, convenceu o governador Mem de Sá a baixar "leis de proteção aos índios", impedindo a sua escravização. Foi nomeado o primeiro provincial da Companhia de Jesus, no Brasil, mas faltando-lhe a saúde foi substituído pelo padre Luís da Grã. Faleceu em 1570.

33 José de Anchieta nasceu na Ilha de Tenerife nas Canarias aos 19 de março de 1534, filho de Juan Lopes de Anchieta, revolucionário basco que participara da revolta dos Comuneros contra o Imperador Carlos V na Espanha, parente dos Loyola. A mãe de José, Mência Dias de Clavijo y Llarena, natural das Ilhas Canárias, era filha de judeus cristãos-novos. Aos quatorze anos, José mudou-se para Coimbra, em Portugal, para estudar Filosofia junto ao Rela Colégio das Artes e Humanidades, anexo à Universidade de Coimbra. Ingressou na Companhia de Jesus em 1551 como irmão; e indicado para o envio ao Brasil pelo Provincial da Ordem Simão Rodrigues, a partir de um pedido de Manoel da Nóbrega quanto ao envio de 
que existem quatro sentidos do uso do termo nestes documentos: experiência como prova e experimento (peiria); experiência como conhecimento, habilidades e praticas derivados da peiria (empiria); experiência como abertura do sensível para o transcendente abrindo ao conhecimento da revelação da ação divina nas circunstâncias da história humana; e experiência modelar (mística) onde acontece a identificação de cada jesuíta com a vivência do fundador e com os valores e os fins da Companhia. Todos estes sentidos são relacionados entre eles, no sentido de serem etapas de um processo unitário que leva ao conhecimento da realidade: desde a experiência como verificação e prova, diante do novo, até sua consolidação num conhecimento adquirido ao longo do tempo que se torna habito e prática; desde a realidade concreta até a realidade transcendente.

\section{Experiência como prova e verificação}

Esta dimensão da experiência é presente nas cartas dos autores jesuítas, sobretudo no que diz respeito ao contacto com aspectos novos da realidade com que se deparam, trata-se ela de realidade antropológica quanto natural.

È este o sentido da expressão utilizada na carta de Nóbrega aos irmãos do colégio de Jesus de Coimbra de 13 de setembro de $1551^{34}$, enviada de Pernambuco, onde relata os primeiros frutos missionários obtidos na evangelização dos escravos, documentável pela mudança de seus hábitos: "porém de tudo o que me alegra mais o espírito é ver por experiência o fruto que se faz nos escravos dos Cristãos, os quais com grande descuido dos seus senhores viviam gentilicamente em graves pecados" 35 . Nos primeiros anos de sua missão esta "experiência do fruto" conseguido, inspira em Nóbrega uma esperança acerca dos sucessos futuros e apóia seus pedidos à Província, de maiores recursos para a missa brasileira.

A experiência alheia também pode ensinar, como mostra Nóbrega na mesma carta: ao insistir acerca da importância de que se realizem casamentos mistos entre colonos e índias na capitânia de Pernambuco, coloca que "hão-se de casar como

\footnotetext{
um maior contingente de missionários. Anchieta chegou ao Brasil em 13 de junho de 1553, junto com outros companheiros na armada de Duarte de Góis, em condições de saúde precárias, esperando numa melhora num clima mais ameno, pois padecia de espinhela caída. Tinha então menos de 20 anos de idade. Logo após a chegada ocupou-se da construção do colégio de Salvador; aprendeu rapidamente a língua tupi compondo a primeira gramática desta "língua geral" da América Portuguesa. Participou, juntamente com Nóbrega, da fundação do colégio de São Paulo, no planalto de Piratininga aos 25 de janeiro de 1554. Ali morou dedicando-se à educação e catequese das crianças indígenas e defendendo os índios dos abusos dos colonizadores que queriam escravizá-los. Esteve também em Itanhaém e Peruíbe, no litoral sul de São Paulo. Em 1563, foi para a aldeia indígena de Iperoig, junto com Nóbrega, em missão de paz, visando intermediar o armistício entre os Tupinambás de Ubatuba, reunidos na confederação dos Tamoios e os portugueses. Ofereceu-se nesta circunstância como refém dos Tamoios em Iperoig. Em 1566 foi enviado para a Capitania da Bahia tendo o encargo de informar o governador Mem de Sá acerca do andamento da guerra contra os franceses no Rio de Janeiro e possibilitando assim o envio de reforços militares aos portugueses. Ordenado sacerdote aos 32 anos, morou no colégio de Rio de Janeiro de 1570 a 1573. Em 1569, fundou a povoação de Reritiba no Espírito Santo (atual Anchieta). Em 1577 foi nomeado Provincial da Companhia de Jesus no Brasil, função que exerceu por dez anos. Dirigiu ainda o Colégio de Vitória no Espírito Santo. Retirou-se para Reritiba onde faleceu em 1597.

${ }^{34}$ Nóbrega, M. 1988.

${ }^{35}$ Nóbrega, Ibidem: 120.
} 
puderem os homens, como a experiência das outras capitanias nos tem ensinado, onde se casaram todas quantas negras forras havia entre Cristãos", ${ }^{36}$

Comenta Zeron ${ }^{37}$ a respeito dos primeiros anos das atividades evangelizadoras dos jesuítas no Brasil, que naquele momento "as cartas remetidas do Brasil por Manuel da Nóbrega e seus companheiros contêm ainda uma visão algo otimista do trabalho catequético”; e, de modo geral, "os comentários sobre as disposições particularmente favoráveis dos índios à conversão e as descrições de batismos em massa realizados em todo o litoral constituem um lugar-comum recorrente das missivas”38.

José de Anchieta, na Breve narração das coisas relativas aos Colégios e residências da Companhia nesta província Brasílica, no ano de $1584,{ }^{39}$ se expressa em termos semelhantes: "Agora me volto para as missões, das quais em toda a parte se colhe um fruto que não é para desprezar, pois que é certo e provado por experiência diária que os nossos nunca arredam pé do colégio, sem que reconduzam para o bom Deus a muitos afastados do caminho da virtude" ${ }^{40}$.

Nos três exemplos aqui apresentados, vemos o recurso à experiência para sustentar os argumentos dos autores quanto ao proveito da missão brasileira e a necessidade de maiores investimentos para sustentá-la: antes de mais nada o envio de um maior número de missionários.

A experiência é também o argumento usado para comprovar a visão de fenômenos naturais inusitados pelos observadores europeus.

Na carta enviada ao Padre Geral da Companhia aos 31 de maio de 1560, no item Fazendo a descrição das inúmeras coisas naturais, que se encontram na província de $S$. Vicente hoje S. Paulo, Anchieta descreve vários fenômenos naturais que são novos aos seus olhos por serem próprios do ambiente tropical. E aqui também usa o termo experiência em várias ocasiões. Ao descrever os métodos de desova utilizados pelos peixes, relata ser algo "muito de admirável, provado pelo testemunho de todos, e verificado por manifesta experiência”: “dez ou doze dos maiores vêm na frente, á superfície da água, como exploradores, percorrendo e examinando o lugar, á ver si ha algum perigo, como si pressentissem alguma cilada, e voltam então, como que para reconduzir seu cardume" ${ }^{41}$. Anchieta refere-se ao fenômeno citando o nome dado-lhe pelos índios e sua explicação: "piráiquê", "isto é, entrada dos peixes; porquanto vêm inúmeros deles de diversas partes do mar, entram para os lugares estreitos e de pouco fundo do mar, afim de porem as ovas”. E introduz a descrição do fenômeno da desova, já relatado no documento que citamos há pouco, afirmando que é algo "admirável, mas unanimemente comprovado e verificado por notória experiência”: “dez ou doze dos maiores sobem á tona da água como exploradores, e olhando e examinando o lugar todo, se porventura lhes fazem alguma ofensa, voltam, como que pressentindo a traição, para conduzir a outra parte o seu rebanho" ${ }^{42}$.

\footnotetext{
${ }^{36}$ Nóbrega, Ibidem: 120.

${ }^{37}$ Zeron, C. A. M.R., 2011.

${ }^{38}$ Zeron, Ibidem: 61.

${ }^{39}$ Anchieta, J. 1988.

40 Anchieta, Ibidem: 61.

${ }^{41}$ Anchieta, 1933/1988: 120-121.

${ }^{42}$ Anchiera, ibidem: 111.
} 
No mesmo relato, trata dos caranguejos e do emprego de sua carne como remédio, usado pelos índios, para a cura da enfermidade do cancro: Anchieta conta que esses "aquecem ao fogo um pouco de barro de panela, bem amassado, e pregam quente, quanto a carne possa tolerar, nas raízes do cancro que morre, pouco a pouco; repetem isto tantas vezes, até que, amortecidas as raízes despegam-se do corpo e caem por si mesmas”. E confirma que a eficácia desta terapia, "se provou pela experiência, um dia destes, em uma criada de portugueses, que sofria desta moléstia" ${ }^{43}$.

Acerca da arvore da copaíba e das propriedades terapêuticas do liquido que dela se retira, Anchieta descreve em pormenores os procedimentos dos nativos para extraí-lo: "o qual, a principio pelos furinhos, feitos pelo caruncho, ou também pelas incisões abertas com facas, ou machadinhos, corre como azeite, depois, coagulando-se, parece apresentar a aparência de balsamo"; comenta que "cheiro que desprende não é muito forte, mas agradabilíssimo" e se refere a suas propriedades terapêuticas: é "excelente para curar feridas, porque nem mesmo restam vestígios de cicatrizes, como dizem que se provou pela experiência"44. A referência à "experiência” dos índios como comprovação das propriedades do balsamo é utilizada, portanto, por Anchieta, neste texto

Cabe frisar esse emprego do termo experiência feito por Anchieta e que nos remete aos métodos de conhecimento da observação da natureza, da filosofia natural, mas também da ciência a ele contemporânea. ${ }^{45}$

Na carta de autoria do Padre Ruy Pereira $\mathrm{SI}^{46}$, escrita do Brasil (Pernambuco), para os Padres e Irmãos da Companhia em Portugal, no dia 15 de setembro de $1560^{47}$, o autor se refere a uma vivência pessoal: aprendeu a usar o método de dormir dos índios, para ele inusitado e que, porém, lhe parece muito conveniente, além de ser-lhe recomendado pelo médico. Escreve: "dir-me-ão que vida pôde ter um homem, dormindo em uma rede, pendurado no ar como rédea de uvas? Digo que é isto cá tão grande cousa que, tendo eu cama de colchões, e aconselhando-me o medico que dormisse na rede, a achei tal que nunca mais pude ver cama, nem descansar noite que nela não dormisse”, devido ao "descanso que nas redes acho". E comprova pela afirmação: "outros terão outros pareceres; mas a experiência me constrange a ser dessa opinião"48.

Aqui a experiência é usada para mostrar o avanço vivenciado quanto ao conhecimento e aos hábitos da realidade local: ao se superar o obvio do mundo-da-vida tradicional e aceitar o novo da alteridade, pode se adquirir uma visão e uso de realidade, ${ }^{49}$ potenciados e mais eficazes.

A experiência como prova é um recurso também no que diz respeito ao conhecimento do mundo antropológico índio cuja novidade se apresenta aos olhos dos

\footnotetext{
${ }^{43}$ Anchieta, J. Ibidem: 112.

${ }^{44}$ Anchieta, J. Ibidem: 136.

45 Para um aprofundamento do papel da experiência neste momento histórico vide Massimi, M. \&Hoffman, 2011.

${ }^{46}$ Ruy Pereira veio ao Brasil em 1559, junto com o segundo bispo Dom Pedro Leitão, e outros religiosos da Companhia, fixando-se em Pernambuco.

${ }^{47}$ Navarro, A. et al, 1988.

${ }^{48}$ Pereira, R. Em: Navarro et alii., 1931/1988: 290.

${ }^{49}$ Para a discussão deste aspecto vide Mahfoud, M.; Massimi, M.; Silva, P.J.C.; Avanci, S., 1997.
} 
missionários como um desafio constante. Mas serve também como argumento para provar a fidelidade aos pactos, e, portanto, a confiabilidade dos índios em seus juramentos.

O jesuíta Antonio Blasquez ${ }^{50}$, numa carta escrita ao Provincial de Portugal da Bahia em 1557, retrata os hábitos antropofágicos das populações e descreve a tintas foscas um desses rituais de que ele mesmo presenciara. Ao referir-se as tentativas feitas pelo governo colonial e pelos missionários de desraigar o hábito antropofágico das populações nativas, conta que numa certa ocasião foi proposto pelo Governador aos índios um contrato em que estes deviam se empenhar em mudar o tratamento reservado nas guerras aos inimigos cativos e valentes, substituindo o ritual antropofágico pelo cativeiro e escravatura: "antes que os Principais se fossem de casa do Governador, aonde foram chamados por este contrato, firmaram todos em um ato publico que se fez, de guardar aquele contrato, scilicet: de não comer carne humana” se comprometendo a respeitar as regras e aceitando de submeter-se a castigos e a ser privados de suas próprias terras, "si inteiramente não o cumprissem". Este contrato foi lido pelas aldeias ao som do tambor. De modo que "ficaram eles d'ali por diante medrosos e com medo de faltar em o que tinham prometido, como por experiência se viu em os Negros, que mataram e não quiseram comer" ${ }^{\text {51. }}$.

\section{Experiência como empiria}

Experiências repetidas de comprovação, ao longo do tempo, dão lugar à “experiência das coisas”, ou seja, a conhecimentos e práticas decorrentes e que dizem respeito principalmente ao convívio social e as relações interpessoais.

Esta dimensão da experiência comparece em várias cartas de Nóbrega, num primeiro momento, logo após a chegada, como algo a ser ainda adquirido; e posteriormente, como algo que adquirido, sustenta decisões e posicionamentos.

Na missiva destinada ao rei português Dom João III, escrita aos 14 de setembro de 1551 de Olinda, Nóbrega descreve sua própria escassez de conhecimento da nova terra, nos primeiros tempos após as chegada no Brasil, nestes termos: "logo que a esta capitania de Duarte Coelho chegamos, outro Padre e eu, escrevi a Vossa Alteza dandolhe alguma informação das cousas desta terra”, mas afirma que estas informações eram falhas "por ser novo nesta capitania e não ter tanta experiência dela” 52 .

Anos mais tarde, na carta enviada ao governador Thomé de Sousa em 1559, onde relata as atividades da Companhia no Brasil, em sua primeira década de presença missionária, Nóbrega avalia os efeitos da missão evangelizadora junto aos índios, afirmando que os resultados negativos atestam a necessidade de emprego de métodos diferentes, como, por exemplo, o recurso a força militar e a constrição. E justifica esta mudança de procedimento a partir da experiência: "e nós agora o começamos de ver a olho por experiência, (...), que, si o deixam em sua liberdade e vontade, como é gente brutal, não se faz nada com eles, como por experiência vimos todo este tempo que com

\footnotetext{
50 Antônio Blasquez, castelhano, vejo ao Brasil em 1553, junto com Padre Luis da Grã. Em 1565 foi enviado em Porto Seguro empenhando-se na educação das crianças indígenas.

${ }^{51}$ Blasquez, A. Em: Navarro, 1931/1988: 196

52 Nóbrega, M. 1931/1988: 133.
} 
ele tratamos com muito trabalho, sem dele tirarmos mais fruto" ${ }^{\text {53 }}$. E, em outras partes do mesmo documento, escreve: "cada dia vemos nesta terra com perdas de barcos e gente comida dos índios, a qual por experiência veio ser mais a que nisso se gasta, que a que se de novo acrescenta á terra" ${ }^{54}$. Que a experiência do fracasso se torne conhecimento é importante para que se pensem mudanças e estratégias para lograr resultados positivos. Zeron assinala que nos anos em que a carta foi escrita, Nóbrega elabora uma nova estratégia missionária. Com efeito, nas cartas jesuíticas, “às descrições iniciais das conversões em massa dos indígenas, sucedem os relatos da desilusão dos missionários ante o retorno os neófitos a seus usos e costumes tradicionais" 55 . Neste período, os “obstáculos externos (em particular as epidemias e os ataques dos colonos contra os aldeamentos)" e as "resistências internas (as cartas nos referem notadamente a fuga, a recidiva e a inconstância dos índios)”, levam os jesuítas a “desesperarem de sua missão" 56 . De modo que, “desde os anos 1550 até o fim dos anos 1560, vê-se multiplicar-se entre os missionários as tomadas de posição (....) por uma estratégia de submissão do índio pela força" ${ }^{57}$.

Mas também, diante deste quadro, Nóbrega apela para a iniciativa divina, cuja intervenção é também comprovada pela experiência: “quando Deus quer ajudar, os amigos se fazem inimigos em favor dos Cristãos, e quando quer castigar, faz dos inimigos amigos: e uma cousa e outra se viu nesta terra por experiência”" ${ }^{58}$.

A crise dos métodos missionários, empregados nos inícios da missão brasileira e a necessidade de se pensar em mudanças quanto aos modos de proceder, aparece também na carta de Nóbrega ao Provincial de Portugal, escrita em 1557, da Bahia: "desde que fui entendendo, por experiência, o pouco que se podia fazer nesta terra na conversão do Gentio, por falta de não serem sujeitos, e ser uma maneira de gente de condição mais de feras bravas que de gente racional, e ser gente servil”,59. E ainda na carta quadrimestral de 1557 destinada ao Padre Geral Inácio de Loyola, da Bahia, Nóbrega insiste que "por experiência vemos que por amor é mui dificultosa a sua conversão, mas, como é gente servil, por medo fazem tudo" ${ }^{\text {60 }}$. E, em carta ao Rei Dom João III de 1552, da Bahia, escreve: "não nos parece bem batizar muitos em multidão, porque a experiência ensina que poucos vêm a lume" ${ }^{\text {61 }}$.

Anchieta, na Breve narração das coisas relativas aos Colégios e residências da Companhia nesta província Brasílica, no ano de 1584, apela à experiência, em termos de um hábito consolidado no que diz respeito a uma prática litúrgica: “pela Quaresma, porém, quatro vezes por semana se reuniu a assembléia, posto que com grande sacrifício por parte dos operários, compensado com tudo, pelo bom fruto dos ouvintes, o qual a experiência mostra que é proveitosíssimo, quando procede da palavra de Deus”62.

\footnotetext{
${ }^{53}$ Nóbrega, M. Ibidem: 193.

${ }^{54}$ Nóbrega, M. Ibidem: 201.

${ }^{55}$ Zeron, C. 1991: 122-123.

${ }^{56}$ Zeron, C. Ibidem: 125.

${ }^{57}$ Zeron, C. Ibidem: 125.

${ }^{58}$ Nóbrega, M. Ibidem: 216.

${ }^{59}$ Nóbrega, M. 1931/1998: 174.

${ }^{60}$ Nóbrega, M. Ibidem: 159.

${ }^{61}$ Nóbrega, M. ibidem: 135.

${ }^{62}$ Anchieta, J. 1933/1988: 58.
} 
O mesmo autor, em Informação dos primeiros aldeamentos da Baía de 1587, relata a mudança ocorrida no governo das aldeias indígenas: houve a substituição dos funcionários régios, pelos padres missionários da Companhia, para remediar ao despovoamento das mesmas pelos nativos. Como se sabe, a aldeia foi uma forma de implantação missionária da Companhia, peculiar da realidade brasileira ${ }^{63}$. Em 1558, Mem de Sá, logo depois de tomar posse como Governador, seguindo o conselho de padre Nóbrega e visando pacificar os índios da Bahia e facilitar o trabalho evangelizador dos jesuítas, dispôs que esses se juntassem em povoações onde residissem também os padres da Companhia. Anchieta sustenta a positividade da mudança de governo pelo malogro da forma anterior exercida pelos funcionários régios: "pela experiência que se viu, que nem os capitães tinham proveito, nem os índios o favor e ajuda que se esperava" ${ }^{64}$. E ainda, recomenda a importância de que para pensar providencias, se tomem as "informações necessárias, assim de pessoas seculares, que tenham experiência das cousas da terra, como dos religiosos da Companhia de Jesus”65. A "experiência das coisas da terra" torna-se assim um importante critério para pensar a política missionária

No texto Informação do Brasil e de suas capitanias (1584). Dos impedimentos para a conversão dos brasis e, depois de convertidos, para o aproveitamento nos costumes e vida cristã, Anchieta usa o termo experiência num sentido análogo ao já colocado por Nóbrega, ao referir-se ao fato de que o método que parece mais conveniente para a cristianização do índio é o recurso ao medo e a submissão: “todos estes impedimentos e costumes são mui fáceis de se tirar se houver temor e sujeição, como se viu por experiência desde o tempo do governador Mem de Sá até agora" "66. Aqui Anchieta apela aos efeitos da política dos aldeamentos promovida por Mem de Sá, para provar que a sujeição é condição necessária à evangelização dos nativos. Ao comentar este texto de Anchieta, Zeron coloca que ele chega a refutar quanto anteriormente afirmado por ele próprio e por Nóbrega acerca da capacidade intelectual e moral dos indígenas. A "idéia da sujeição pelo medo" ${ }^{67}$ adotada dali em diante, repousa justamente no argumento da "experiência da terra”.

Mas nem sempre os jesuítas fazem apelo à experiência para referir-se a aspetos negativos do convívio com os índios. Na carta de Jorge Rodrigues ${ }^{68}$, escrita de Ilhéus, aos 21 de Agosto de 1565, e destinada a padres e irmãos da Companhia de Jesus de Portugal, ele se refere a experiência para designar o conhecimento já adquirido da religiosidade dos nativos: "a gente desta terra procede muito bem in via Domini, é devota e amiga de Deus, segundo a experiência deste pouco tempo que ha que estou aqui me dá a entender."69

Analogamente, se expressa em carta da Bahia (1565), o Padre Antônio Blasquez, dirigindo-se ao Padre Provincial de Portugal, ao referir-se a adesão dos índios às

\footnotetext{
${ }^{63}$ Observa a este respeito Castelnau: “Il s'agit em effet dês villages regroupant dês Indiens sous l'autorité dês missionnaires qui lês évangélisent tout en le ‘civilizant”” Em: Castelnau-L”Estoile, Ch., 2000: 48.

${ }^{64}$ Anchieta, J. 1933/1988: 358.

${ }^{65}$ Anchieta, J. Ibidem: 367.

${ }^{66}$ Anchieta, J. ibidem: 341.

${ }^{67}$ Zeron, C. 2011: 127.

68 Jorge Rodrigues veio como irmão em missão em 1559 junto com o segundo bispo Dom Pedro Leitão. Ordenado sacerdote, foi professor de latim no colégio de Salvador e depois trabalhou na aldeia de Santo Antônio.

${ }^{69}$ Rodrigues, J. Em Navarro et alii, 1931/1988: 494.
} 
práticas religiosas da confissão: "se tem visto por experiência que, como continuam este exercício, se aproveitam grandemente, de maneira que em saberem confessar-se e tomar bem o que lhes dizem, levam aos Brancos vantagem, segundo tenho dos Padres línguas entendido daqueles que se querem aproveitar, e isto porque naturalmente têm boa condição" ${ }^{70}$.

Este mesmo autor, em carta escrita da Bahia em abril de 1558, destinada ao Padre Geral, e redigida por comissão do Padre Nóbrega, ao reprovar a violência dos colonos para com os índios, refuta a tese destes que justificam a sua má conduta por um presumido medo do levante dos nativos: "cousa muito fora de caminho para quem tem experiência dos índios e vê o grande temor deles e poder dos Cristãos"71. A “experiência dos índios” torna-se assim um conhecimento importante para regrar a conduta social e a política. Mas esta mesma experiência não seria suficiente para infundir nos missionários confiança acerca de sua obra, se eles não contassem com uma superação da experiência mundana e com a possibilidade de interpretar os acontecimentos experienciados como sinais do designo divino na história humana.

\section{Da experiência sensível a experiência mística}

A experiência pode se tornar revelação da ação divina na história humana, na medida em que se saiba ler os sinais desta ação. Em vários casos, esta ação é relatada como "o espírito de Deus que move”. A formação e a vivência dos jesuítas tornam-nos capazes de ler e atuar a partir desta hermenêutica da realidade mundana. Podemos aplicar aos autores das cartas quanto Pécora ${ }^{72}$ afirma acerca da consciência histórica do pregador jesuíta Antônio Vieira: para este, assim como para os autores por nós estudados, o valor da história é sacramental, remete ao mistério da divina providência, sendo este "o modo dramático que combina a urgência da salvação com a consciência dos perigos". De modo que "o real imediato e visível”, "expande os seus limites com a ponderação misteriosa de seu fundamento, conservação e finalidade"73. Os "fatos históricos são lugares da presença divina" "74, mas lugar velado, cabendo aos homens iluminados pela divina graça, a possibilidade de revelar seu sentido último. Neste sendo, a experiência adquire a sua espessura completa na medida em que remete a dimensão mística, à dimensão do mistério de que participa, do qual se origina e ao qual é destinada.

As figuras exemplares da Companhia são retratadas justamente enfatizando nelas esta capacidade de "serem movidas pelo espírito de Deus", documentável na experiência. Por exemplo, Anchieta nos referidos Fragmentos históricos, em apontamentos dedicados a historiar a biografia de Manoel da Nóbrega, ao relatar e aprovar a decisão de Nóbrega de adquirir gado para o sustento da Companhia no Brasil, de maneira a lograr certa independência da Coroa, afirma que "bem mostra a experiência o espírito de Deus que o movia”. Com efeito, a medida tomada por Nóbrega propiciaria que desse modo, os Colégios da Baía e Rio tivessem mais adequada sustentação "com que se criam tantos Irmãos que fazem tantos serviços a Deus no

\footnotetext{
${ }^{70}$ Blasquez, A. Em Navarro ET alii, idem: 466

${ }^{71}$ Ibidem: 207.

${ }^{72}$ Pécora, A., 1994.

${ }^{73}$ Ibidem: 265.

${ }^{74}$ Ibidem: 170.
} 
Brasil” ${ }^{\text {75 }}$. Análoga expressão é usada por Anchieta no mesmo documento, ao referir-se a insistência de Nóbrega junto ao governador Mem de Sá para que usasse a força militar para ajuntar os índios da Bahia em aldeamentos regidos pelos missionários: "a experiência tem mostrado ser ele movido com o espírito de Deus e puro zelo de seu serviço e salvação das almas”. (idem, p. 479). Anchieta diz que este discernimento do “espírito de Deus" evidente nas ações de Nóbrega pela experiência, brotava nele também da receber pela oração "mais particular lume de Deus"76.

A este discernimento da vontade divina no meio das circunstâncias humanas comprovada pela experiência, refere-ser também numa carta da Bahia destinada aos irmãos de Portugal em 1552, Padre Francisco Pires ${ }^{77}$. Pires escreve da Bahia e relata uma tentativa de viagem missionária empreendida de barco por Nóbrega e Manoel de Paiva na direção de São Vicente; Pires conta que a decisão da viagem fora "movida pelo desejo que (Nóbrega) tinha de os ver a todos e consolar-se com seus Irmãos” do que "por ser vontade de Deus Nosso Senhor", como os acontecimentos evidenciaram. Tendo sido o barco forçado a voltar pelas mudanças climáticas, Nóbrega decidira junto com a comunidade de não realizar uma viagem missionária e que depois "a experiência ensinou ser muito gloria de Nosso Senhor não ir ele, por cousas que sucederam" ${ }^{78}$. O discernimento dos desígnios da Providência através das circunstâncias, inclusive naturais, apóia-se na comprovação que a experiência fornece. De modo que a sintonia dos leitores da hermenêutica divina se evidencia ainda mais.

A experiência de um jesuíta, quando conduzida segundo o percurso formativo da Companhia, se torna união mística e experiência modelar, que imita os exemplos de Cristo e dos padres fundadores. Todavia, esta união mística não é tanto de natureza interior, mas se revela na experiência dos fatos, históricos, sociais e naturais.

Em carta da Bahia de 30 de maio de 1564, para o padre Provincial de Portugal, escrita por comissão de Padre Nóbrega, António Blasquez assim sintetiza os bons êxitos da missão da Companhia no Brasil:

E assim acontece que, depois do torvelinho e tempestade, dá o Senhor a tranqüilidade e bonança, e depois da escuridão e trevas mostra a luz e claridade, permitindo que precedam primeiro estes trabalhos para que nos sejam mais saborosas as e consolações presentes, como agora sentimos por experiência, porque, conforme á grandeza das dores proximamente passadas abundam agora ás consolações em nós outros, vendo tantas almas entrarem no redil de Cristo para se fazerem cristãs, e o que muito alegra e consola é que se continuam os batismos solenes ${ }^{79}$.

A eficácia da experiência missionária é comprovada em base as mesmas categorias da consolação e da desolação que moldam a vida espiritual do jesuíta: com efeito, a busca da imitação de Cristo, da identificação e adesão a Ele vividas no âmago da ação missionária, traz uma experiência de consolação. A este respeito, vale lembrar

\footnotetext{
${ }^{75}$ Anchieta, J., 1933/1988: 475.

${ }^{76}$ Ibidem: 481.

77 Padre Francisco Pires veio ao Brasil em 1552; estabeleceu-se em Porto Seguro onde fundou a Capela de Nossa Senhora da Ajuda; foi bom pregador e também diretor do Colégio de Salvador. Faleceu em 1586.

${ }^{78}$ Pires, F. Em: Navarro et alii 1931/1988: 153.

${ }^{79}$ Blasquez, A. Em Navarro et alii, 1931/1988: 431.
} 
quanto Pacheco observa acerca do fato de que a espiritualidade jesuítica se funda na "experiência imediata, é preciso o conhecimento direto proporcionado pelos sentidos e pela consciência de si mesmo, é preciso a experiência das coisas percebidas, que são conhecidas na medida em que as vivemos, as tocamos, ouvimos, experimentamos... "sentir y gustar de les cosas internamente ". ${ }^{80}$

Leonardo do Valle ${ }^{81}$ em carta escrita da Bahia para o da Companhia de Jesus do Colégio de São Roque em Lisboa, aos 26 de junho de 1562, descreve a experiência vivida pelos missionários entre os índios, onde o sacrifício e a fadiga são transfigurados em "gostos e descansos": refere-se aos irmãos missionários como "aqueles que por experiência têm bem visto e conhecido que estes são seus gostos e descansos; posto que, comumente, quanto á carne nos tais tempos sofreu grandíssimos trabalhos, porque lhe custa perder o sono e tempo em que é necessário dar refeição ao corpo, e fazer de muita parte da noite, dia com a diversidade de negócios que então sobre ele carregam" ${ }^{82}$. O tom exortativo e edificante desta carta é evidenciado por algumas expressões utilizadas onde os "grandíssimos trabalhos" e sacrifícios são chamados de "brandas camas e mimos" ${ }^{\prime 3}$.

\section{Conclusão}

Na perspectiva dos jesuítas, "tudo o que aqui se dá, e não poderia senão dar-se aqui, ganha seu sentido (ou sua direção) quando localiza em sua existência o efeito-sinal

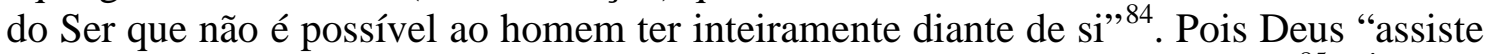
o mundo muito de perto (...) a ponto de assinalar-se em toda ocorrência” ${ }^{85}$. É neste horizonte último que se coloca o sentido da experiência.

Para finalizar nosso percurso, comparamos quanto lemos nas cartas dos missionários jesuítas com as reflexões de outro jesuíta que nunca viajou para as missões, mas que vivera sua atividade intelectual como uma grande viagem espiritual: Daniello Bartoli. Nascido em Ferrara (1608-1685), foi um eminente cientista-literato italiano. Jesuíta e historiador oficial da Companhia de Jesus, Bartoli tinha também grande paixão pela física e pela matemática. Entende a contemplação da natureza como um exercício espiritual, tendo o fim último de reconhecer a marca divina no mundo criado: o mundo é um livro escrito por Deus, cuja leitura é possível ao homem sábio. Nesse sentido, a experiência do mundo só é completa para quem sabe lê-lo como sinal, conforme o autor evidencia neste trecho do tratado Dell'uomo di lettere difeso ed emendato (1645), especialmente no capítulo Il gusto dell'intendere spiegato, per saggio dell'altre scienze, nella sola cognizione dei cieli:

Eis o que acontece a quem se maravilha, ao admirar este belíssimo rosto da natureza que é o céu e descobrir a maneira como Deus desenhou na matéria sensível conforme a capacidade dela, traços de tão rara beleza, copiando-os de si mesmo. Assim o engenho de quem admira o céu, é totalmente tomado

\footnotetext{
${ }^{80}$ Pacheco cita a este respeito, García Mateo, R., 1998.

${ }^{81} \mathrm{O}$ irmão Leonardo do Valle tinha grande conhecimento dos idiomas indígenas; viveu suas atividades missionárias em São Vicente e na Bahia, nas aldeias de Rio Vermelho e de São João.

${ }^{82}$ Valle, L.em: Navarro et alii, 1931/1988: 372.

${ }^{83}$ Ibidem.

${ }^{84}$ Pécora, A. 1992: 161.

${ }^{85}$ Ibidem, p. 162.
} 
pela contemplação desta beleza, os pensamentos ficam estáticos e a mente satisfeita. Todavia, se todos admiram o céu, nem todos conseguem entendelo. Pois há uma distância enorme entre quem entende e quem não entende: o primeiro enxerga completamente o céu como uma escritura em letra arábica feita em ouro e azul, o segundo vê apenas os caracteres e as frase, mas não entende sua beleza e seu pleno sentido ${ }^{86}$.

No homem sábio, o percurso do conhecimento conduzido pela razão, incansavelmente, relaciona os dados e extrai deles resultados, desembocando numa atividade contemplativa que termina na mística. Bártoli afirma que diante do desconhecido e do mistério que também se evidenciam na experiência, "o pesquisador nunca se deve perder de ânimo, nunca deve perder a esperança”, pois "somente quem fez experiência desta espera, poderá saber qual seja a experiência do deleite proporcionado pelo encontro com uma verdade procurada longamente e com muita fadiga”. Com efeito, "esta verdade ficará muito mais saborosa, do que se fosse recebida como dom imediatamente oferecido à nossa mente” ${ }^{\text {" }}$.

A experiência, vivida dentro de seu horizonte ultimo é capaz de proporcionar ao homem aquele conhecimento do bem que orienta a ação constantemente, como Inácio de Loyola testemunha de si mesmo, em seu relato autobiográfico: “colheu, então, por experiência, que de uns pensamentos ficava triste e de outros, alegre. Assim veio pouco a pouco a conhecer a diversidade dos espíritos que o moviam, um do demônio e outro de Deus” ${ }^{88}$. E é na experiência que a ação orientada para o bem, revela os seus frutos: "O contentamento que nesta vida pode haver mostra a experiência que o acham não os frouxos, mas os fervorosos no serviço de Deus" ${ }^{89}$. Desse modo, podemos realmente entender que a experiência mencionada pelos missionários jesuítas em suas cartas do Brasil é realmente uma experiência modelar, na seqüela de Inácio pelas sendas da terra brasilis.

\section{Referências}

Agostinho (2000), Trindade. (A. Belmonte, Introdução. e Trad.), São Paulo: Paulus. (Original de 416 d.C.).

Anchieta, José. SI (1988), Cartas Inéditas, Instituto Histórico e Geográfico de São Paulo Edição comemorativa do quarto centenário São Paulo: Tipografia da Casa Eclética, 1900.

\footnotetext{
${ }^{86}$ Bartoli, D. Em: Raimondi, E. 1965: 323. Texto original: "Eccovi quello che interviene a chi stupisce come, in mirando quel bellissimo volto della natura, il cielo, in cui Iddio, quanto n'era capace materia sensibile, disegnó, copiandoli da sé, lineamenti di sí rare bellezze, possa trovarsi materia di godimento che ne resti assorto l'ingegno, estatici i pensieri e beata la mente. Tutti mirano il cielo, ma non tutti l'intendono; e v'é fra chi l'intende e chi no, que divario che corre fra due, dei quali l'uno d'una scrittura arabica tratteggiata d'oro e miniata d'azzurro altro non vede che il lavorio de' ben composti caratteri, l'altro di piú ne legge i periodi e ne intende i sensi, talché il minor de' piaceri che gode é quello degli occhi."

${ }^{87}$ Bártoli. Em Raimondi, 1965: 627-628.

${ }^{88}$ Loyola, I.1974: 22.

${ }^{89}$ Loyola, I. Em: Cardoso, A. SI, 1990: 45.
} 
Bartoli, D. Em: Raimondi, E. (1965), Trattatisti e narratori del Seicento, Napoli: Ricciardi.

Caeiro, F. G. (1982), “O pensamento filosófico do século XVI ao século XVIII em Portugal e no Brasil”, Acta do l Congresso Luso-Brasileiro de Filosofia. (pp. 5190). Braga: Revista Portuguesa de Filosofia; Caeiro, F. G. (1989). El problema de las raíces históricas. Em: E. M. Barba e col. Iberoamerica, una comunidad. (pp. 377-389). Madrid: Ediciones de Cultura Hispánica.

Castelnau-L"Estoile, Ch. (2000), Lês ouvriers d'une vigne stérile. Lês jésuites et la conversion dês Indiens ao Brésil, Lisboa-Paris: Centre Culturel Calouste Goulbenkian.

Cardoso, A. SI (1990), Carta aos padres e irmão de Coimbra 7 de maio de 1547. Em Cardoso, C. Cartas de Inácio de Loyola. vol. 2. São Paulo: Editora Loyola.

Craveiro, L. SI. (1665), Merenda eucarística e sermão que pregou o padre Lourenço Craveiro da Companhia de Jesus, da Província do Brasil, do Colégio da Bahia, no terceiro dia das quarenta horas á tarde em 16 de fevereiro de 1665 . Deu á estampa o P. Fr. Antonio Craveiro pregador e religioso capucho da Ordem de Nosso Seráfico Padre São Francisco da Província de Granada.

Fabris, A. (1997), Esperienza e mistica. Em:A. Molinaro e E. Salman. Filosofia e mistica: itinerari di un progetto di ricerca. (pp. 13-28), Roma: Pontificio Ateneo Sant'Anselmo.

García Mateo, R. (1998), Fuentes filosófico-teológicas de los ejercicios según el currículum académico de su autor. Em J. Plazaola (Ed.) (1998). Las fuentes de los Ejercicios Espirituales de San Ignacio. Actas del Simposio Internacional (Loyola, 15-19 septiembre 1997). (pp. 467-508), Bilbao: Ediciones Mensajero pp. 478-479.

Góis, M. (2005), Sobre os três livros do Tratado de Alma de Aristóteles Stagirita. Commentarii Collegii Conimbricensis Societatis Iesu, In tres libros de Anima, Aristotelis Stagiritae. Organizado e traduzido por Santiago, M\& Camps, M. Lisboa: Edições Sílabo. (Conimbricae: Typis et expensis Antonii a Mariz Vniuersitatis Typographi. Original de 1598)

Góis, M. (1957), Disputas do curso sobre os livros da ética a Nicômaco, de Aristóteles em que se contêm alguns dos principais capítulos da Moral. (A B. Andrade, Trado.), Lisboa: Instituto de Alta Cultura. (Original publicado em 1593).

Góis, M. (1607), Commentarii Collegii Conimbricensis Societatis Iesu in Libro de Generatione et Corruptione Aristotelis Stagiritae nunc recens omni diligentia recogniti et emendati. Venezia: Vincenzo Amadino.

Góis, M. (1593), Commentarii Collegii Conimbricensis Societatis Iesu, in Libros Aristotelis qui Parva Naturalia appellantur, Lisboa: Simão Lopes; Góis, M. (1602), Commentarii Collegii Conimbricensis Societati Iesu, in tres Libros de Anima, Venezia: Vincenzo Amadino.

Guibert, J. (1953), La spiritualité de la Compagnie de Jésus: esquisse historique. Em IHSI (org.), Bibliotheca Instituti Historici Societatis Iesu (Vol. IV, pp. XL-659). 
Romae: IHSI.

Gusmão, A. (1720), Eleyçam entre o Bem e o Mal Eterno. Lisboa: Officina da Musica.

Lamalle, E. (2004), Compagnia di Gesù. Totus Tuus Network - Pagine cattoliche. Retirado em 15/07/2013, do World Wide Web: http://www.paginecattoliche.it / CompagniaDiGesù.htm.

Loyola, I. (1991), Écrits (M. Giuliani, Pres. et Dir.). Paris: Desclée de Brouwer; Bellarmin, (Collection Christus, 76, Textes), (Originais de 1510 a 1556). (p. 142).

Marin, L. (1999), Le Récit, réflexion sur un testament. Em L. Marin. L'écriture de soi: Ignace de Loyola, Montaigne, Stendhal, Roland Barthes. (pp. 137-155), Paris: PUF.

Loyola, I. (1974), Autobiografia, trad. Port. São Paulo: Editora Loyola, pag. 22, para 6 cap.1.

Loyola, .I. Em: Cardoso, A. SI (1990), Cartas. Carta aos padres e irmão de Coimbra 7 de maio de 1547, vol. 2, São Paulo: Editora Loyola.

Massimi, M. (2000), La psicologia dei temperamenti nei Cataloghi Triennali dei gesuiti in Brasile, Physis, Rivista Internazionale di Storia della Scienza,37, 137-150.

Massimi, M.; Mahfoud, M.; Silva, P. C. J.; Avanci, S. H. S. (1997), Navegadores, colonos, missionários na Terra de Santa Cruz: um estudo psicológico da correspondência epistolar, São Paulo: Loyola.

Massimi, M. \& Mahfoud, M. (2007), A pessoa como sujeito da experiência: um percurso na história dos saberes psicológicos. Memorandum, 13, 16-31. Retirado em 09/07/2013, da World Wide Web http://www.fafich.ufmg.br/ memorandum/a13/massimimahfoud01.pdf

Massimi, M. \&Hoffman, (2011), A. Ciência - da maravilha a descoberta. Ribeirão Preto: Editora Funpec.

Navarro, A. et alii, (1988), Cartas avulsas. Cartas jesuíticas 1560-1568. Publicações da academia brasileira, Belo Horizonte - São Paulo: Editora Itatiaia-Edusp (primeira edição de 1931).

Nóbrega, M. SI (1988), Cartas do Brasil 1549-1560. Belo Horizonte - São Paulo: Editora Itatiaia - Edusp. (Original de 1931, Publicações da Academia Brasileira Cartas Jesuíticas Rio de Janeiro, Oficina Industrial gráfica).

Pacheco, P.R.A. (2004), Experiência como fator de conhecimento na psicologiafilosófica aristotélico-tomista da Companhia de Jesus (séculos XVI-XVII). Memorandum, 7, 58-87. Retirado em 18/07/2013, do World Wide Web: http://www.fafich.ufmg.br/ memorandum/artigos07/pacheco01.htmp. 60.

Pécora, A. (1992), Teatro do sacramento, São Paulo: Edusp.

Pécora, A. (1999), Cartas à Segunda Escolástica. Em A. Novaes (Org.). A outra margem do Ocidente. (pp. 373-414), São Paulo: Companhia das Letras.

Pécora, A. (2001), Máquina de gêneros: novamente descoberta e aplicada a Castiglione, 
Della Casa, Nóbrega, Camões, Vieira, La Rochefoucauld, Gonzaga, Silva Alvarenga e Bocage. São Paulo: Editora da Universidade de São Paulo.

Zeron, C. A. M.R.(2011), Linha de fé. A Companhia de Jesus e a escravidão no processo de formação da sociedade colonial (Brasil, séculos XVI e XVII), São Paulo: Edusp. 